\title{
Activistas clasistas en las fábricas del calzado de la Córdoba revolucionaria (1969-1975)
}

\author{
María Laura Ortiz \\ (UBA / CONICET) \\ malauraortiz@gmail.com
}

Este artículo forma parte de un trabajo más amplio, que tiene por objetivo analizar históricamente la tendencia sindical clasista, esto es, abordar sus dinámicas a partir de las transformaciones políticas, sociales y culturales que sucedieron en Córdoba entre 1969 y 1976. Si bien el sindicalismo clasista se manifestó en distintos espacios y momentos históricos, tuvo un desarrollo excepcional en Córdoba durante el período examinado. James Brennan y Mónica Gordillo sostienen que esta excepcionalidad reside en la profunda radicalización de algunos sindicatos en comparación con otros de Argentina y de América Latina (Brennan y Gordillo, 2008: 251). No obstante, un repaso por otras experiencias clasistas desarrolladas en Buenos Aires y Santa Fe demuestra que allí también hubo niveles muy altos de radicalidad (Löbbe, 2009; Lorenz, 2013; Santela y Andújar, 2007; Schneider, 2005; Werner y Aguirre, 2009). Estas fueron experiencias posteriores a la de Córdoba $y$, en algunos casos, tuvieron a ésta como ejemplo. De manera que la particularidad de Córdoba tuvo más que ver con su desarrollo temprano, en un clima de profunda movilización política posterior al "Cordobazo". Por ello, comprender los procesos sucedidos en Córdoba en el periodo 1969-1975 es sustancial para entender el devenir nacional.

Conviene aclarar que, académicamente, no abundan las reflexiones sobre el concepto "clasismo" (Ortiz, 2010). Algunos autores lo definen a partir de su sentido ideológico, considerándolo un salto cualitativo en la conciencia de clase. Desde esa perspectiva, el clasismo se vincula con la opción por la izquierda y el camino revolucionario al socialismo, oponiéndose a la tradicional identidad peronista de las masas trabajadoras (Andújar, 1998: 95; Brennan, 1992: 5-15; Brennan y Gordillo, 2008: 257; Duval, 2001: 7-8; James, 2005: 310; Schneider, 2005: 333; Werner y Aguirre, 2009: 86). Otros investigadores, en cambio, han remarcado las limitaciones de esas aseveraciones cuando se las contrasta

(Archivos, año III, $\mathrm{n}^{\circ}$ 6, pp. 139-154) 
con los datos históricos. Según esta otra interpretación, el clasismo es definido más por sus prácticas que por sus definiciones ideológicas, especialmente la apelación a la acción directa, las "huelgas salvajes", la constitución de redes horizontales y/o territoriales, entre otras (Ceruti y Resels, 2006: 125-130; Lorenz, 2013: 115-118).

En Córdoba hemos registrado expresiones clasistas en distintas fábricas mecánicas y metalúrgicas, del vidrio, del calzado, del caucho, en establecimientos lácteos, de la carne, en obras de construcción y en el sector de la sanidad. La diversidad de experiencias registradas dificulta una definición univoca del término "clasismo" aunque, sin embargo, hay una serie de repertorios de confrontación que nos permiten asociarlas. A partir de la nueva etapa histórica que se abrió con el Cordobazo en 1969, se generaron más posibilidades para que las agrupaciones clasistas pudiesen ganar lugares de liderazgo en comisiones directivas de sindicatos de $1^{\circ}$ y $2^{\circ}$ grado, no obstante hasta 1972 lo hacian a partir de una militancia clandestina y por fuera de las estructuras sindicales. El activismo clasista se conjugó con militantes marxistas y peronistas de izquierda, pero a partir de la nueva coyuntura que se despliega con el régimen democrático en 1973, adquieren un renovado protagonismo los peronistas combativos, disputando espacios sindicales que tradicionalmente eran ganados por los peronistas "ortodoxos". ${ }^{1}$ En 1974 se inició la clausura de las direcciones sindicales para los clasistas, a partir del plenario "normalizador" de la Confederación General del Trabajo (CGT) regional y las intervenciones a algunos sindicatos clasistas y combativos. Esa pérdida de espacios institucionales no implicó directamente la "derrota" del clasismo, que continuó movilizado hasta 1975. No obstante, el terrorismo de Estado que el "Navarrazo" hizo posible, fue recortando cada vez más los espacios de expresión para los clasistas.

En esta oportunidad, específicamente, abordaremos el caso del clasismo que tuvo lugar en algunas fábricas de calzado en Córdoba. El clasismo no sólo fue un fenómeno que se desarrolló en grandes complejos industriales ubicados en el sector dinámico de la economía regional, cuya relevancia les permitía una mayor capacidad de negociación. El sector del calzado, como otros que no analizamos en esta oportunidad, formaban parte de los sectores vegetativos de la economía y, sin embargo, ese lugar en el mercado no imposibilitó la capacidad de movilización de las bases, e incluso, la adopción de tendencias clasistas.

El objetivo de este trabajo es analizar la mutua determinación entre las organizaciones clasistas y las cambiantes configuraciones de las

1. El peronismo "ortodoxo" se definía por su característica adhesión intransigente a los principios peronistas y al verticalismo. Con el tiempo, fueron virando hacia posturas facciosas, ideológicamente alineados a la derecha. 
cúpulas sindicales locales -como también nacionales- ${ }^{2}$ para analizar los horizontes de posibilidad de las expresiones clasistas en fábricas de calzado en Córdoba, entre los años 1969 y 1975.

\section{Las cúpulas sindicales cordobesas en el contexto revolucionario}

Con el Cordobazo se expresó un bloque socio-político antidictatorial, que aceleró un proceso de exteriorización y expansión de la protesta. Fue la expresión de un pasaje de la resistencia a la confrontación, de la defensiva a la ofensiva; donde las reivindicaciones se expresaban en consignas que excedian lo sectorial y que se plasmaron en una serie de proyectos de revolución (Tortti, 1998: 21-22; Pozzi y Schneider, 2000: 53). Mucho se ha escrito y discutido acerca de ese hecho histórico: para algunos el Cordobazo fue el punto final de una serie de luchas sociales que se venían manifestando desde 1956 (Garzón Maceda, 1994: 26); pero, para otros autores, fue el "mito" fundante de las luchas políticas que atravesaron a todo el país hasta marzo de 1976 (Altamirano, 1994: 12; Brennan y Gordillo, 1994: 73-74). Lo cierto es que luego de esa insurrección popular, Córdoba no volvió a ser la misma, como así tampoco las representaciones que el resto del país construyó sobre esta ciudad. Para la mayoría de los proyectos de las organizaciones de la izquierda, el Cordobazo fue un hito fundamental que marcó la construcción de una imagen de la ciudad de Córdoba como "vanguardia" en el proceso revolucionario. A partir de él se construyó una mística revolucionaria representada por los obreros y los estudiantes en las calles, que se acentuó en los años siguientes con un aumento cualitativo y cuantitativo del número de militantes y simpatizantes de partidos de izquierda (Brennan y Gordillo, 1994:104-105). Dentro del ámbito sindical, retomando el trabajo de Daniel James, este proceso se tradujo en la mudanza del tradicional verticalismo por reclamos de autonomía y democratización de los sindicatos hacia un proceso de irrupción de las bases en las plantas fabriles (James, 2005: 299-301). E incluso, trascendiendo las reivindicaciones antiburocráticas, se ampliaron los reclamos hacia objetivos claros de revolución y de implantación de un régimen socialista.

En el momento de producirse el Cordobazo, la regional de la CGT estaba liderada por sectores alineados en el peronismo, tanto del sector "ortodoxo" como de la corriente "legalista". Entre ellos se encontraba la dirigencia del Sindicato del Calzado seccional Córdoba, que estaba presidido desde hacía más de dos décadas por Raúl Olmedo, referente del núcleo "ortodoxo" de las 62 Organizaciones peronistas.

2. Sobre el concepto de determinación, ver Williams, 2001: 262-263. 
No obstante, entre 1969 y1971, las movilizaciones cada vez más radicalizadas de las bases obreras fueron transformando esos posicionamientos en la cúpula de la CGT regional, al elevarse críticas que ponían en cuestión el nivel de compromiso de la central obrera en la defensa de los trabajadores. Un caso fue la "huelga larga" de junio de 1970, desarrollada en fábricas encuadradas en el Sindicato de Mecánicos y Afines del Transporte Automotor (SMATA), con foco en las plantas de Grandes Motores Diesel y Perdriel. El desenlace del conflicto fue percibido por las bases como una derrota, y se responsabilizó por ella a su secretario general Elpidio Torres, referente de la tradicional dirigencia sindical vandorista. Por la misma época, una movilización de las bases obreras en Fiat Concord comenzó a poner en cuestión a su dirigencia. En junio se sumaron sus compañeros de Fiat Materfer, y a partir de allí el Sindicato de Trabajadores de Concord y Materfer (Sitrac y Sitram) actuaron como partes de una misma entidad, aunque eran dos sindicatos de planta. Dos nuevas insurrecciones obreras y populares marcaron el paso de la presión de las bases obreras hacia las dirigencias peronistas: el "Ferreyrazo" primero y, a los pocos días, el "Viborazo" (Duval, 2001: 46-50; Flores, 2004: 174-189).

Además, los conflictos internos en la dirigencia sindical peronista debilitaban su conducción. En este tiempo habian resurgido tensiones entre "ortodoxos" y "legalistas" dentro de las 62 Organizaciones Peronistas por la discusión sobre qué vinculación se debía mantener con los núcleos no peronistas. Para los "ortodoxos" se debía prescindir de los no peronistas -principalmente los "independientes", muchos de ellos comunistas y radicales-; pero los "legalistas" buscaban consolidar alianzas con estos otros sectores.

Las movilizaciones clasistas, aglutinadas sindicalmente en el sector "no alineado", hicieron posible la visualización pública de críticas sobre el estilo dirigencial que tradicionalmente había administrado la vida sindical, y que ocupaba la cúpula de la CGT local y nacional. Si bien durante 1970 los "no alineados" mantuvieron sus distancias con el sector de los sindicatos identificados como "independientes" -cuyo principal referente era Agustín Tosco, dirigente del Sindicato de Luz y Fuerza-, a partir de 1972-1973 se establecieron alianzas estratégicas entre estos dos nucleamientos, especialmente con la conformación del Movimiento Sindical Combativo (MSC).

Esta alianza entre el peronismo "legalista" y los "independientes" logró ganar el secretariado de la central obrera local en 1971, liderada por el peronista combativo Atilio López y el líder de los "independientes" Agustín Tosco. Aunque Tosco fue detenido y encarcelado por más de un año y medio, sin poder hacerse cargo en lo concreto de esta función; la CGT continuó en la misma sintonía política de combatividad y alianza 
de diferentes nucleamientos. Si bien uno de los principales motivos que unía a peronistas "legalistas", radicales y comunistas era la lucha contra la dictadura y la legislación represiva, de a poco fueron incorporando otras reivindicaciones como el levantamiento de las intervenciones en los sindicatos, el pedido de apertura de las discusiones paritarias, el reclamo contra la carestía de vida e, incluso, la necesidad de generar conciencia e identidad de clase. A partir de 1973 se sumó al secretariado de la CGT regional, René Salamanca, secretario general del SMATA; sellando la alianza de los sectores clasistas y combativos en la cúpula de la central obrera local. Esta nueva conducción en la CGT fue el resultado de una movilización de bases obreras que había iniciado unos años antes, aunque también su presencia fue una condición de posibilidad para que, en diferentes sindicatos, se alzasen voces opositoras a sus dirigencias "ortodoxas", como sucedió en el Sindicato del Calzado.

A partir de 1973 las elecciones transformaron el panorama sindical cordobés, ya que Atilio López, cuya trayectoria política estaba ligada a su participación como dirigente del sindicato de conductores de ómnibus (Unión Tranviarios Automotor), fue electo como vicegobernador. Ese lugar ponderó a los "legalistas" en sus disputas con los "ortodoxos", tanto en el campo político como en el mundo sindical, del que el caso del Sindicato del Calzado seccional Córdoba es un ejemplo. De ese movimiento oposicional a las cúpulas sindicales tradicionales también participaron nucleamientos identificados con la izquierda revolucionaria, aunque tuvieron a su vez otros conflictos en su relación con el gobierno provincial, sobre todo porque éste no llegó a desarrollar una política de empleo interpelada por la conflictividad laboral del momento.

La interrupción violenta del gobierno de Ricardo Obregón Cano y Atilio López tampoco mejoró la situación de los trabajadores. El 28 de febrero de 1974 el por entonces Jefe de la Policía provincial, Tte. Cnel. (re) Antonio Domingo Navarro, derrocó al gobierno de Córdoba que había sido elegido democráticamente diez meses antes. Luego, el presidente Juan D. Perón -con aprobación del Congreso- ordenó la intervención federal de la provincia (Ortiz, 2013: 83-88). Este cambio en lo político se vio reflejado en lo sindical, y tuvo como hito el plenario "normalizador" de la CGT regional Córdoba, realizado en Alta Gracia el mismo día del Navarrazo. Su Secretariado, que había sido consensuado previamente en el ámbito de "las 62", estaría formado únicamente con peronistas: cuatro serían representantes de la fracción "legalista" y cuatro de la "ortodoxa". La vuelta de Perón a la presidencia, en septiembre de 1973, les había dado los apoyos políticos necesarios para prescindir de los no peronistas. De hecho, sindicatos "independientes" como Luz y Fuerza, Empleados Públicos, el Círculo de Prensa (CISPREN) y los clasistas de Perkins no pudieron participar de la reunión en Alta Gracia. Sin em- 
bargo, fueron reconocidos como representantes algunos interventores de sindicatos, como el del Calzado. Pero dos días antes del plenario se rompió el acuerdo entre "legalistas" y "ortodoxos" y, finalmente, los primeros quedaron afuera del nuevo Secretariado de la CGT. Además, los cuatro dirigentes "legalistas" que habian sido preseleccionados para conformar el Secretariado fueron detenidos durante el putsch policial. A partir de ese momento, la coordinación estatal de la represión con razones políticas transformó la protesta social e izquierdista, esta vez, de la ofensiva a la defensiva.

La configuración de las cúpulas sindicales, sobre todo a nivel local, fue determinante en el horizonte de posibilidades del clasismo. Mientras la hegemonía era peronista, entre 1969 y 1971, las posibilidades de organización institucional de las agrupaciones clasistas fueron más limitadas. Pero a partir de 1971, con una nueva dirección en la CGT regional que aglutinaba peronistas combativos, "independientes" y clasistas, emergieron mayores posibilidades de expresión para el clasismo, aunque el peronismo "ortodoxo" sería un obstáculo dificil de sortear para lograr institucionalizar la organización clasista. El quiebre de 1974 acortó los espacios de disputa, ya que el sector "ortodoxo" logró dominar nuevamente las cúpulas sindicales regionales.

\section{La producción de calzado en Córdoba y el surgimiento del activismo clasista}

Según el Censo Nacional Económico de 1974 la producción de calzado de cuero en Córdoba representaba el 1,31\% del total de la producción industrial de la provincia. Es decir que tenía un lugar secundario en la industria de Córdoba, cuyas actividades más dinámicas giraban en torno de la producción metalúrgica y metalmecánica (ver Tabla $\mathrm{n}^{\circ} 1$, pg. 154). A pesar de no pertenecer a las ramas dinámicas de la economía regional, la producción de calzado condensaba al $2.7 \%$ del total de la masa trabajadora de la industria (ver Tabla $\mathrm{n}^{\circ} 2$, pg. 154). Además, por las características de la actividad, la mayor parte de sus trabajadoras eran mujeres, lo que le da una especificidad al sector, a diferencia del resto de las actividades productivas cuya población trabajadora tenía una preponderancia masculina. La mayor cantidad de talleres y fábricas de calzado se concentraban en el sureste de la ciudad de Córdoba, sobre todo en barrio Colón y San Vicente. Por su ubicación territorial, tuvieron muchos contactos con los clasistas de Fiat, con quienes se movilizaron conjuntamente en más de una oportunidad. Más allá de todas estas características, o a pesar de ellas, durante los años de mayor protesta obrera en Córdoba, las bases de trabajadores de este sector se vieron movilizadas al compás de los trabajadores de otros sectores, sea de 
sectores dinámicos o no. Quizás la causalidad de estos movimientos de irrupción de las bases no haya que buscarla en la estructura económica, sino en el marco de posibilidades politicas para emerger.

En este recorrido discutiremos la hipótesis de Mónica Gordillo y James Brennan, para quienes el clasismo o la combatividad de un sindicato se corresponde con su lugar preponderante en el mercado productivo $\mathrm{y}$, especialmente, entre los sectores más dinámicos de la economía por su mayor capacidad de negociación (Gordillo, 1996: 57-58; Brennan y Gordillo, 2008: 31). Consideramos que aquella situación en el mercado no fue determinante para la constitución de un movimiento de "rebelión de las bases", parafraseando a Daniel James (2005: 299-301); ni mucho menos que ese movimiento desembocase en una expresión clasista o, en el mejor de los casos, en una dirección clasista en un sindicato.

En estos establecimientos fabriles la arbitrariedad patronal y las malas condiciones laborales parecían ser una tradición, como también lo era la pasividad sindical ante estas situaciones. Era común la obligatoriedad de firmar los recibos de sueldo en blanco, los despidos sin causa o la falta de seguridad en las máquinas. Ante estas situaciones el sindicato debía intervenir, solicitando inspecciones de organismos estatales en las plantas, o bien reclamar ante la patronal el cumplimiento de la legislación laboral. Pero, como ello no sucedia, los trabajadores podian recurrir al apoyo de otros sindicatos o de la regional de la CGT o bien autoorganizarse.

En 1970 hallamos los primeros ejercicios de resistencia y autoorganización de las bases de las fábricas del calzado. En la fábrica Italo Brenna, ubicada en Barrio Colón, la patronal quiso obligar a sus trabajadores a cambiar el horario laboral, fraccionando la jornada que era continuada. Las bases resistieron el cambio de horario y por ello la empresa decidió despedir a 39 obreras. Un grupo importante de sus 101 trabajadoras acudieron a la CGT y denunciaron, además, que el dueño de la fábrica, que era un militar retirado, pagaba $\$ 800$ de sueldo en vez de pagar los $\$ 1.300$ que correspondian. También expusieron que era común que las obligaran a firmar recibos de sueldo en blanco o por sumas diferentes a las que recibian, completándolos después con la suma que convenía para poder evadir impuestos. Alli los feriados se trabajaban como jornada simple y los sábados no se consideraban trabajo extra; y esos días no se permitía marcar tarjeta para evitar el registro de esas ilegalidades ( $L a$ Voz del Interior, en adelante LVI, 18 de septiembre de 1970: 20). Raúl Olmedo, presidente del Sindicato del Calzado, fue apuntado como cómplice de la situación de injusticia, que continuó durante todo el período (Córdoba, 12 de junio de 1971: 13).

Estas expresiones de bases obreras buscaron su constitución como oposición sindical a la "camarilla" de Olmedo. Pero los estatutos y las 
prácticas de la Unión Trabajadores de la Industria del Calzado de la República Argentina les dificultaban la tarea: desde hacía 24 años se presentaba una sola lista, la Azul y Blanca; y nadie podía disputarle el liderazgo. Por ello buscaron organizarse por fuera de la estructura sindical, convocando a opositores de diferentes plantas a reuniones al margen de las asambleas del Sindicato (LVI, 15 de diciembre de 1970: 13; Córdoba, 24 de junio de 1971: 13).

En julio de 1971 se formó la Agrupación de Obreros del Calzado "11 de junio" que se definía como la "agrupación que interpreta la voluntad de las bases", y declaraba:

Que hemos salido a la lucha en defensa de la organización sindical que nos agrupa, en manos de seudos dirigentes que han convertido al Gremio del Calzado en una sucursal de los intereses patronales [...] La unión con todos los hombres honestos del gremio es una de nuestras metas (Córdoba, 4 de julio de 1971, p. 27).

Por aquellos años, la honestidad era sinónimo de movimiento de bases y de clasismo; y por el contrario, la corrupción se asociaba a la "burocracia". La Agrupación "1 1 de Junio", apoyada por el Sindicato de Empleados Públicos (SEP), la CGT regional y el Sitrac-Sitram, convocó a una asamblea y propuso realizarla en el Sindicato de Vendedores de Diarios. Cuando la asamblea se constituyó, sin la presencia de ningún miembro de la conducción -aunque sí estuvo el hijo de Raúl Olmedo tratando de impedir el libre ingreso de los trabajadores-, circuló la versión de que los directivos habian "huido junto a Olmedo en búsqueda de la Policia". Por ello decidieron mudarse al local de la CGT regional: allí se destituyó a la Comisión Administrativa por "inconducta sindical y deslealtad" y se designó una Comisión Administrativa Provisoria (Córdoba, 12 de julio de 1971: 15; Córdoba, 14 de julio de 1971: 13).

Hasta aquí el proceso de "rebelión de las bases" es bastante similar al caso de Fiat Concord y Materfer en Córdoba, esto es, se inició con un proceso de autoorganización de las bases por fuera y al margen del sindicato, formando una Comisión Provisoria para destituir a la dirección sindical existente (Duval, 2001; Flores, 2004). Sin embargo, comparando el caso del Calzado con el proceso vivido en Fiat, los trabajadores de base del calzado hallaron apoyos sustanciales en la CGT regional, que prestaba sus espacios y recursos para su organización. Es que, como explicamos ut supra, la CGT que se había conformado en Córdoba en 1971 era diferente a la 1970. Por otro lado, el del calzado era un sindicato por rama de producción, por lo que dependía de la Comisión Central de la Unión Trabajadores de la Industria del Calzado. Es decir que la 
autonomía relativa que tenían los sindicatos de Fiat, por ser Sindicatos por planta, no se parecía a la que tenían en el calzado. Por ello, para que la Comisión Provisoria del calzado fuese reconocida, debía ser aprobada por la Central. Ésta, al igual que la dirección regional, estaba alineada con el peronismo "ortodoxo" y, en vez de reconocer la comisión formada por las bases, envió una Comisión Interventora a la seccional cordobesa. Para ello se basó en las acusaciones de Olmedo, que los había tildado de "extremistas, guerrilleros, extranjerizantes" de "conocida filiación comunista" ajenos al gremio. No obstante, la Comisión Provisoria sí fue reconocida en el Departamento de Trabajo, donde negoció con la patronal de la firma Blanco Hnos., logrando dejar sin efecto el despido arbitrario de dos obreros y obteniendo el compromiso de respetar la legislación laboral vigente (Córdoba, 16 de julio de 1971: 13).

Para formar la Comisión Interventora, la Central envió a Córdoba gente de Capital Federal, Avellaneda y Rosario. Al principio, esta comisión se diferenciaba de la anterior dirección, y se jactaban de haber denunciado incumplimientos de las disposiciones laborales en que incurrian numerosas patronales y de haber reorganizado los cuerpos de delegados de las fábricas de calzado Lucas Trejo, Triay Hermanos, Dimaja y Blanco Hermanos. Al principio, la Agrupación "11 de junio" apoyó la intervención y suspendió la Comisión Provisoria, pero al poco tiempo comenzó a criticarla, argumentando que no eran trabajadores del gremio, en especial sus asesores Pedro Albisini y Montesana. En su lugar, proponían formar una "comisión asesora" elegida por las bases y movilizaron a los trabajadores para reclamar la mejora de condiciones laborales.

Esta Comisión Interventora comenzó a tener diferencias con el cuerpo de delegados de la fábrica Lucas Trejo, a partir del conflicto que se desarrolló en ese establecimiento. De todas las fábricas de calzado de Córdoba, Lucas Trejo es una de las más recordadas por sus conflictos, por su activismo, porque establecieron redes horizontales con sindicatos clasistas como los de Fiat, y porque la gran mayoria de sus delegadas eran mujeres.

En Lucas Trejo, al igual que en muchas otras fábricas del sector, la arbitrariedad patronal era una constante. Pero en 1971 las bases comenzaron a organizarse y a reclamar sus derechos. El inicio del conflicto sucedió cuando la patronal despidió al subdelegado Luis Ramón Toledo, por lo que se dispuso una huelga de brazos caídos durante ese día. Pero, luego del descanso del mediodía, cuando se presentaron a continuar con la jornada, se encontraron con la fábrica cerrada, un cordón policial al frente y 170 telegramas de despido. Unos dias después, los trabajadores de Fiat Concord hicieron abandono de tareas en solidaridad con este conflicto, marchando desde Ferreyra hasta 
el Barrio San Vicente donde estaba ubicada la fábrica y, desde allí, marcharon juntos con el Movimiento Clasista de Obreros del Calzado $\mathrm{y}$ algunos vecinos del barrio.

El conflicto continuó en los días siguientes, cuando la Agrupación "11 de junio" y el Cuerpo de Delegados de Lucas Trejo convocaron a un paro activo con un acto frente al local de la CGT regional, que fue acatado masivamente a pesar de las presiones y amenazas de las patronales. Con el impulso del cuerpo de delegados del establecimiento Lucas Trejo y del Movimiento Clasista Obreros del Calzado, una asamblea de trabajadores terminó expulsando a Montesana, el dirigente de la Comisión Interventora. En cada reunión, en cada acción, las trabajadoras de Lucas Trejo tenían el apoyo de los Sindicatos de Fiat, de la CGT regional y también de la UTA, que les prestaban sus locales y daban asesoramiento, lo que era catalogado por la Comisión Interventora como intromisión "extremista" (Duval, 2001: 63).

Los enfrentamientos continuaron y, acorde al período histórico, combinaron la discusión con la violencia política. Así, un par de días más tarde un grupo de unas 20 personas "patoteó" a unas 400 obreras del calzado que se habian congregado en una asamblea en el hall del local de la CGT regional. Hubo disparos de armas de fuego y bombas de estruendo, combinadas con golpes de puño y puntapiés a algunas trabajadoras que estaban en la escalera del local. El grupo agresor se identificaba con la escarapela argentina, y fueron calificados por los agredidos como "supuestos nacionalistas que se autotitulaban 'peronistas ortodoxos" pero que, según los agredidos, eran "bandas fascistas armadas por la Policía del régimen y pagadas por las patronales". La Agrupación "11 de junio" emitió un comunicado en el que responsabilizaba a la Intervención del Sindicato del Calzado a convocar a matones a sueldo para intimidar a los trabajadores (LVI, 28 de agosto de 1971: 10; Duval, 2001: 62).

Este hecho demuestra al menos dos cosas. Primero, que la organización de las bases del calzado era capaz de reunir a cuatro centenas de trabajadores en una asamblea, cifra más que significativa considerando que debe haber reunido trabajadores de distintas fábricas, que en general tenían desde menos de 100 hasta no mucho más de 300 obreros. Vale decir que ya estaban en funcionamiento las redes horizontales propias del clasismo en la época, por fuera y al margen de los sindicatos, reuniendo al activismo, cuerpos de delegados y comisiones internas. Segundo, que los trabajadores de bases del calzado se enfrentaban a la cúpula de su propio sindicato, alineada al peronismo "ortodoxo"; y que eran apoyados por la CGT regional y otros sindicatos, alineados al peronismo combativo, al sindicalismo "independiente" y clasista.

Había al menos dos sectores enfrentados a la Comisión Interventora 
del calzado. Uno era el Movimiento de Recuperación del Calzado, que toma su nombre de los movimientos clasistas de la época. Sus activistas, algunos de ellos militantes de partidos de la izquierda revolucionaria, eran calificados por los normalizadores como "permanentes provocadores" y, a principios de 1972, fueron atacados a tiros por parte de autoridades del sindicato mientras realizaban una asamblea (Córdoba, 26 de marzo de 1972: 4). ${ }^{3} \mathrm{El}$ otro sector era la Agrupación Obrera del Calzado "11 de junio", dirigida por Armando Jorge D'llelo. Formada principalmente por militantes peronistas, estaba alineada en "las 62 legalistas" y, desde 1973, tenía buenas relaciones con el vicegobernador Atilio López que la apoyaba en sus críticas a la comisión normalizadora.

A pesar de esos apoyos, las agrupaciones de bases tenían un funcionamiento extrainstitucional, ya que formalmente el sindicato estaba intervenido. En esa situación se hacía más dificil mejorar las condiciones laborales y salariales de los trabajadores que, como hemos mencionado, estaban marcadas por una fuerte arbitrariedad patronal. Aun así, la oposición a la intervención nunca dejó de bregar por la organización de las bases para defender sus derechos. Por ejemplo, ante el incendio de la fábrica Triay comenzaron a circular versiones de que la empresa suspendería a todo el personal por dos o tres meses y luego despediría al 50\% sin indemnización. Por ello el Movimiento de Recuperación del Sindicato del Calzado convocó a los trabajadores a organizar una Comisión Interna. Por su parte, la Agrupación "11 de junio" denunciaba despidos de delegados en la fábrica Bruno Landi y Nando, como también suspensiones sin término en Italo Brenna, Blanco, Larami y Fábrica Muñoz. En estas últimas también se denunciaba que los obreros no podían elegir delegados ni tampoco eran amparados por el sindicato. Criticaban a la Comisión Interventora del gremio porque tenía "dirigentes que nada han hecho para mejorar la nefasta conducción de Olmedo sino que por el contrario continúan aplicando la misma política sindical tramposa en perjuicio de los obreros" (Córdoba, 29 de julio de 1972: 5). El vicegobernador Atilio López los apoyó en sus declaraciones, y acusó que el gremio del calzado estaba dirigido por personas ajenas al quehacer específico. Eso provocó la respuesta de la Comisión Interventora, que declaró que la Comisión Directiva Central de UTICRA habia nombrado como interventor de la seccional Córdoba a Armando Pesenti, quien venía de ser Secretario General del Sindicato en Rosario. Según manifestaban,

3. Por la misma época, hubo Movimientos de Recuperación en el SMATA, en Perkins, en el Sindicato de Empleados Públicos (SEP) y en el Sindicato Único de Empleados y Obreros de la Municipalidad de Córdoba (SUOEM). Durante este período también existieron expresiones clasistas, aunque sin estos membretes, en agrupaciones que se formaron en el Sindicato de la Construcción, en el Sindicato del Caucho, Metalúrgicos, Gráficos y Lecheros. 
Pesenti habría sido el encargado de nombrar a la Comisión Interventora, formada con obreros del calzado y afiliados al gremio (Córdoba, 27 de junio de 1973: 4).

En la misma sintonía con ese movimiento de oposición a la intervención, actuaron algunas organizaciones políticas y político-militares, especialmente el Peronismo de Base y el Ejército Revolucionario del Pueblo (ERP), que contaban con algunos militantes entre sus trabajadores (L.U., Bizzi y Sosa). El ERP efectuó varios copamientos y arengas en fábricas de calzado: en octubre de 1973 en la fábrica Lucas Trejo se hizo una arenga al personal, distribuyendo propaganda "guerrillera". Dos meses más tarde la misma fábrica fue copada por el Comando Eduardo Giménez del ERP que también arengó a su personal, distribuyó propaganda revolucionaria y recibió "la más cálida simpatía de los trabajadores" (Estrella Roja, No 27, 17 de diciembre de 1973: 15). También en la fábrica de zapatillas Bartolo Ludovico en Barrio San Vicente hubo una arenga por parte de un grupo de 4 personas de "filiación guerrillera" que pintaron paredes y repartieron volantes (Córdoba, 8 de noviembre de 1973: 4).

Para los empresarios del sector, la mala situación de los trabajadores y los despidos se debían a una crisis generalizada de esta rama productiva. Según sus argumentos, estaban siendo perjudicados por la obligatoriedad de comprar materia prima y maquinaria en Buenos Aires, lo que aumentaba los costos de producción. En efecto, la patronal de Lucas Trejo había manifestado que, ante esta situación, debería cerrar definitivamente la planta y, por ello, los delegados, asesorados por el Dr. Curutchet, solicitaron al gobierno la expropiación de la fábrica para reactivar y reabrir la fuente de trabajo. Ese pedido quedó suspendido por un tiempo, desde septiembre de 1971 hasta agosto de 1975, ciertamente, debido a los vaivenes políticos de la provincia. Finalmente, en el contexto posterior al Navarrazo, el gobierno de la intervención federal compró la fábrica con la idea de crear talleres sociales coordinados por el ministerio de Bienestar Social. Pero el hecho fue investigado a pedido del bloque de diputados provinciales de la Unión Cívica Radical (UCR), y de esa investigación se constataron graves irregularidades en el cumplimiento de los deberes de funcionario público por parte del ministro de Bienestar Social, como también irregularidades en el manejo de los fondos públicos.

A mediados de 1975 la sangría por despidos continuaba, según las denuncias de la Agrupación de Trabajadores del Calzado (Córdoba, 2 de agosto de 1975: 4). ${ }^{4} \mathrm{El}$ sindicato no se movilizaba contra los des-

4. También la Agrupación de Trabajadores del Calzado denunció el despido arbitrario de 42 trabajadores de la fábrica de calzados El Dante de barrio San Vicente y de otros en otras fábricas (Córdoba, 7 de agosto de 1975: 5). 
pidos y frenaba las denuncias colectivas de las bases, en una clara "actitud pro-patronal". A pesar de sus dirigentes, los trabajadores del calzado continuaron activos durante este período, y llegaron incluso a ocupar seis fábricas por reclamo de mejoras laborales y salariales. La conducción del sindicato no apoyó estas tomas aunque luego, cuando consideró que la situación era irreversible, declaró un paro por 48 horas y reclamó el pago de indemnizaciones y salarios caídos. Esta actitud tenía más que ver con un intento de "administrar los descontentos" de las bases antes que con una real movilización en búsqueda de mejoras para los trabajadores (James, 2005: 333-334). En este caso, al igual que en otros sindicatos intervenidos, como el SMATA de Córdoba y otros, los cuerpos orgánicos y la movilización de las bases comenzaron a funcionar de manera autónoma respecto de la cúpula sindical. En el caso del calzado, la institucionalidad sindical se mantuvo alineada a la verticalidad "ortodoxa" del peronismo que, desde 1974, había vuelto a hegemonizar el campo político.

$$
* * *
$$

Aunque no se trataba de uno de los sectores más dinámicos de la industria cordobesa, el sector de producción de calzado tuvo un rol significativo en el movimiento obrero de la Córdoba revolucionaria y movilizada del post Cordobazo. Durante los meses posteriores a la conmoción provocada por el Cordobazo, las cúpulas sindicales locales -en las que predominaba la tendencia peronista- limitaban las posibilidades de intervención institucional de los clasistas. Por ello, los trabajadores de fábricas de calzado buscaron autoorganizarse por fuera de la estructura sindical, conforme a la estrategia clasista del momento histórico. Formaron comisiones propias de las bases, organizadas a partir de la intervención de activistas identificados con el clasismo y con el peronismo "legalista" y combativo. Aunque tuvieron reconocimiento del Estado, no lograron que la central del Sindicato los admitiera y, en cambio, se envió una Comisión Interventora que fue eficaz para evadir las expresiones de las bases obreras. Acompañando esa táctica, el discurso de la dirigencia sindical tradicional culpaba a los clasistas de infiltrados, comunistas, extremistas, legitimando su marginación de las instituciones obreras. Con el Navarrazo se garantizó una nueva hegemonía sindical y política de los sectores identificados con el peronismo ortodoxo. La "normalización" de la CGT regional bajo la órbita ortodoxa, dio un reconocimiento legal a la Intervención en el Sindicato del Calzado, dejando a las agrupaciones de bases fuera del marco institucional del sindicalismo local.

Es decir que, si bien la coyuntura abierta a partir de 1971 con una 
dirección combativa en la CGT regional aportó posibilidades de emergencia para el clasismo en este sector, al mismo tiempo, el verticalismo de los peronistas ortodoxos de la central del sindicato del calzado obturaron las posibilidades de institucionalización de estas expresiones. No obstante, los Cuerpos de Delegados y agrupaciones clasistas fueron sustanciales para sostener la movilización de las bases hasta mediados de 1975, funcionando como entes autónomos de la intervención.

\section{Bibliografia}

Altamirano, Carlos (1994), "Memoria del 69", Estudios, N 4, diciembre, Córdoba, pp. 9-13.

Andújar, Andrea (1998), "Combates y experiencias: las luchas obreras en Villa Constitución (1974-1975)", Taller, vol. 3, n 6, abril, Buenos Aires, pp. 93-146.

Brennan, James P. (1992), "El clasismo y los obreros. El contexto fabril del 'sindicalismo de liberación' en la industria automotriz cordobesa, 1970-75”, Desarrollo Económico, vol. 32, no 125 (abril-junio), pp. 3-22.

Brennan, James y Mónica Gordillo (1994), "Protesta obrera, rebelión popular e insurrección urbana en la Argentina: el Cordobazo", Estudios, $\mathrm{n}^{\circ} 4$, diciembre, Córdoba, pp. 51-74.

- (2008), Córdoba rebelde. El Cordobazo, el clasismo y la movilización social, Buenos Aires: De la Campana.

Ceruti, Leónidas y Mariano Resels (2006), Democracia directa y gestión obrera. El S.O.E.P.U., la Intersindical de San Lorenzo y la Coordinadora de Gremios, 1962-1976, Rosario: Ediciones del Castillo.

Duval, Natalia (2001), Los sindicatos clasistas: Sitrac (1970-1971), Córdoba: Fundación Pedro Milesi.

Flores, Gregorio (2004), SITRAC-SITRAM. La lucha del clasismo contra la burocracia sindical, Córdoba: Editorial Espartaco.

Garzón Maceda, Lucio (1994), "Cordobazo: algunos de sus mitos y leyendas", Estudios, $\mathrm{n}^{\circ}$ 4, diciembre, Córdoba, pp. 25-34.

Gordillo, Mónica (1996), Córdoba en los 60: la experiencia del sindicalismo combativo, Córdoba: Dirección General de Publicaciones de la UNC.

James, Daniel (2005), Resistencia e integración. El peronismo y la clase trabajadora argentina, 1946-1976, Buenos Aires: Siglo XXI.

Löbbe, Héctor (2009), La guerrilla fabril: clase obrera e izquierda en la Coordinadora de Zona Norte del Gran Buenos Aires: 1975-1976, Buenos Aires: Ediciones RyR.

Lorenz, Federico (2013), Algo parecido a la felicidad. Una historia de la lucha de la clase trabajadora durante la década del setenta (1973-1979). Buenos Aires: Edhasa.

Ortiz, María Laura (2010), "Apuntes para una definición del clasismo. Córdoba, 1969-1976”, en Conflicto Social, año 3, n 3, junio, Instituto 
de Investigaciones Gino Germani, Facultad de Ciencias Sociales, UBA. Disponible en http://webiigg.sociales.uba.ar/conflictosocial/revista/03/ sumario3.htm

Ortiz, María Laura (2013), "Recuerdos y olvidos sobre el terrorismo de Estado. Córdoba, Argentina, 1974-1976", en Robson Laverdi y Mariana Mastrángelo (comps.), Desde las profundidades de la historia oral: Argentina, Brasil y Uruguay, Buenos Aires: Imago Mundi-RELAHO.

Pozzi, Pablo y Alejandro Schneider (2000), Los “setentistas". Izquierda y clase obrera (1969-1976), Buenos Aires: EUDEBA.

Santella, Agustin y Andrea Andújar (2007), El Perón de la fábrica éramos nosotros. Las luchas metalúrgicas de Villa Constitución, 1970-1976, Buenos Aires: Desde el Subte.

Schneider, Alejandro (2005), Los compañeros. Trabajadores, izquierda y peronismo. 1955-1973, Buenos Aires: Imago Mundi.

Tortti, Maria Cristina (1998), "Protesta social y 'nueva izquierda' en la Argentina del Gran Acuerdo Nacional", Taller. Revista de Sociedad, Cultura y Politica, vol. 3, $\mathrm{n}^{\circ}$ 6, Buenos Aires.

Werner, Ruth y Facundo Aguirre (2009), Insurgencia obrera en la Argentina, 1969-1976. Clasismo, coordinadoras interfabriles y estrategias de la izquierda, Buenos Aires: Ediciones IPS.

Williams, Raymond (2001), Cultura y sociedad, 1780-1950. De Coleridge a Orwell, Buenos Aires: Ediciones Nueva Visión.

$$
* * *
$$

Titulo: Classist activists in the shoe factories of revolutionary Córdoba

Resumen: En este artículo analizaremos la conformación de un movimiento de bases clasista en fábricas de Calzado en Córdoba, entre los años 1969 y 1975. Abordaremos sus formas de organización y los principales conflictos que los enfrentaron a las patronales y las cúpulas sindicales, tanto locales como nacionales. A partir de ellos, analizaremos los horizontes de posibilidad tanto para la emergencia de expresiones clasistas, como para institucionalizar su organización.

Palabras clave: Clasismo - Obreros - Calzado - Córdoba

Abstract: In this article we will discuss the formation of 'clasista' movement in footwear factories in Cordoba, between 1969 and 1975. We address their organizational forms and the main conflicts that confronted the employer and local and national union leaders. From them, we will explore the horizons of possibility for the emergence of both class expressions, to institutionalize their organization.

Keywords: Clasism - Workers - Footwear - Córdoba

Recepción: 18 de mayo de 2014. Aprobación: 6 de diciembre de 2014 . 
Tabla N 1. Actividades industriales en Córdoba, 1974

\begin{tabular}{|l|c|c|}
\hline Actividad & $\begin{array}{c}\text { Valor agregado } \\
\text { censal }\end{array}$ & Porcentaje \\
\hline Productos alimenticios, bebidas y tabaco & 1.125 .544 & $19,02 \%$ \\
\hline Textiles, prendas de vestir e industria del cuero & 212.961 & $3,60 \%$ \\
\hline Fabricación de calzado de cuero & $\mathbf{7 7 . 5 8 6}$ & $\mathbf{1 , 3 1 \%}$ \\
\hline Industria de la madera y productos de la madera & 103.998 & $1,76 \%$ \\
\hline $\begin{array}{l}\text { Fabricación de papel y productos de papel, } \\
\text { imprentas y editoriales }\end{array}$ & 151.700 & $2,56 \%$ \\
\hline $\begin{array}{l}\text { Fabricación de sustancias químicas y de productos } \\
\text { químicos derivados del petróleo y del carbón, de caucho } \\
\text { y de plástico }\end{array}$ & 315.518 & $5,33 \%$ \\
\hline $\begin{array}{l}\text { Fabricación de productos minerales no metálicos, } \\
\text { exceptuando los derivados del petróleo y del carbón }\end{array}$ & 460.079 & $7,78 \%$ \\
\hline Industrias metálicas básicas & 107.717 & $1,82 \%$ \\
\hline Fabricación de productos metálicos, maquinaria y equipo & 3.418 .772 & $57,79 \%$ \\
\hline Otras industrias manufactureras & 20.068 & $0,34 \%$ \\
\hline Total & 5.916 .357 & $100,00 \%$ \\
\hline
\end{tabular}

Fuente: elaboración propia, a partir de Censo Nacional Económico 1974, Instituto Nacional de Estadísticas y Censos, Dirección de Informática, Estadística y Censos de Córdoba.

\section{Tabla $\mathrm{N}^{\circ}$ 2. Cantidad de personal ocupado por rama de actividad, Córdoba 1974}

\begin{tabular}{|l|c|c|}
\hline Actividad & $\begin{array}{c}\text { Cantidad de personal } \\
\text { ocupado }\end{array}$ & Porcentaje \\
\hline Productos alimenticios, bebidas y tabaco & 24.385 & $19,78 \%$ \\
\hline Textiles, prendas de vestir e industria del cuero & 9.268 & $7,52 \%$ \\
\hline Fabricación de calzado de cuero & $\mathbf{3 . 3 2 1}$ & $\mathbf{2 , 6 9 \%}$ \\
\hline Industria de la madera y productos de la madera & 5.374 & $2,36 \%$ \\
\hline $\begin{array}{l}\text { Fabricación de papel y productos de papel, imprentas y } \\
\text { editoriales }\end{array}$ & 3.150 & $3,53 \%$ \\
\hline $\begin{array}{l}\text { Fabricación de sustancias químicas y de productos } \\
\text { químicos derivados del petróleo y del carbón, de caucho } \\
\text { y de plástico }\end{array}$ & 4.849 & $10,80 \%$ \\
\hline $\begin{array}{l}\text { Fabricación de productos minerales no metálicos, } \\
\text { exceptuando los derivados del petróleo y del carbón }\end{array}$ & 13.309 & $1,94 \%$ \\
\hline Industrias metálicas básicas & 2.390 & $48,26 \%$ \\
\hline Fabricación de productos metálicos, maquinaria y equipo & 59.480 & $0,85 \%$ \\
\hline Otras industrias manufactureras & 1.044 & $100,00 \%$ \\
\hline Total & 123.249 & \\
\hline
\end{tabular}

Fuente: elaboración propia, a partir de Censo Nacional Económico 1974, Instituto Nacional de Estadísticas y Censos, Dirección de Informática, Estadística y Censos de Córdoba. 